University of Nebraska - Lincoln

DigitalCommons@University of Nebraska - Lincoln

Faculty Papers and Publications in Animal

Science

Animal Science Department

2008

\title{
Estimation of genetic parameters for average daily gain using models with competition effects
}

\author{
C. Y. Chen \\ University of Nebraska-Lincoln \\ Stephen D. Kachman \\ University of Nebraska-Lincoln, steve.kachman@unl.edu \\ Rodger K. Johnson \\ University of Nebraska-Lincoln, rjohnson5@unl.edu \\ S. Newman \\ Genus-Pig Improvement Company (PIC) NA, Hendersonville, TN \\ L. Dale Van Vleck \\ University of Nebraska-Lincoln, dvan-vleck1@unl.edu
}

Follow this and additional works at: https://digitalcommons.unl.edu/animalscifacpub

Part of the Animal Sciences Commons

Chen, C. Y.; Kachman, Stephen D.; Johnson, Rodger K.; Newman, S.; and Van Vleck, L. Dale, "Estimation of genetic parameters for average daily gain using models with competition effects" (2008). Faculty Papers and Publications in Animal Science. 452.

https://digitalcommons.unl.edu/animalscifacpub/452

This Article is brought to you for free and open access by the Animal Science Department at DigitalCommons@University of Nebraska - Lincoln. It has been accepted for inclusion in Faculty Papers and Publications in Animal Science by an authorized administrator of DigitalCommons@University of Nebraska - Lincoln. 


\title{
Estimation of genetic parameters for average daily gain using models with competition effects
}

\author{
C. Y. Chen,* S. D. Kachman, † R. K. Johnson,* S. Newman, and L. D. Van Vleck* ${ }^{1}$ \\ *Department of Animal Science, University of Nebraska, Lincoln 68583-0908; †Department of Statistics, \\ University of Nebraska, Lincoln 68583-0963; \$Genus-Pig Improvement Company (PIC) NA, Hendersonville, \\ TN 37075; and §Roman L. Hruska US Meat Animal Research Center, ARS-USDA, Lincoln, NE 68583-0908
}

\begin{abstract}
Components of variance for ADG with models including competition effects were estimated from data provided by the Pig Improvement Company on 11,235 pigs from 4 selected lines of swine. Fifteen pigs with average age of $71 \mathrm{~d}$ were randomly assigned to a pen by line and sex and taken off test after approximately $89 \mathrm{~d}$ (off-test BW ranged from 61 to 158 $\mathrm{kg}$ ). Models included fixed effects of line, sex, and contemporary group and initial test age as a covariate, with random direct genetic, competition (genetic and environmental), pen, litter, and residual effects. With the full model, variances attributable to direct, directcompetition, genetic competition, and litter (co)variance components could be partitioned; genetic competition variance was small but statistically significantly different from zero. Variances attributable to environmental competition, pen, and residual effects could not be partitioned, but combinations of these environmental variances were estimable. Variances could be partitioned with either pen effects or environmental competition effects in the model. Environmental competition effects seemed to be the source of variance associated
\end{abstract}

with pens. With pen as a fixed effect and without environmental competition effects in the model, genetic components of variance could not be partitioned, but combinations of genetic (co)variances were estimable. With both pen and environmental competition effects ignored, estimates of direct-competition and genetic competition (co)variance components were greatly inflated. With competition (genetic and environmental) effects ignored, the estimate of pen variance increased by $39 \%$, with little change in estimates of direct genetic or residual variance. When both pen and competition (genetic and environmental) effects were dropped from the model, variance attributable to direct genetic effects was inflated. Estimates of variance attributable to competition effects were small in this study. Including environmental competition effects as permanent environmental effects in the model did not change estimates of genetic (co)variances. We concluded that including either pen effects or environmental competition effects as random effects in the model avoids bias in estimates of genetic variances but that including pen effects is much easier.

Key words: competition, genetic parameter, swine

(C)2008 American Society of Animal Science. All rights reserved.

J. Anim. Sci. 2008. 86:2525-2530 doi:10.2527/jas.2007-0660

\section{INTRODUCTION}

Response to selection when performance (especially growth traits) is measured in pens can be affected by embedded competition effects. Mixed model equations incorporating competition effects were presented for animals by Muir and Schinckel (2002) to predict direct and competition genetic effects allowing for individual selection with an index. The applications and consequences of combined breeding programs for forest trees and animals have been reviewed (Muir, 2005). Bijma and Muir (2006) extended methods for evaluating re-

\footnotetext{
${ }^{1}$ Corresponding author: lvanvleck@unlnotes.unl.edu

Received October 17, 2007.

Accepted May 29, 2008.
}

sponse to selection with competition genetic effects and for use of mixed model equations with a quantitative genetic framework. Separation of components of variance is a challenge because of confounding of embedded competition effects in a group with other effects. Van Vleck and Cassady (2005) showed by simulation that estimates of other components of variance can be biased when either pen or competition effects are ignored. Van Vleck et al. (2007) found confounding of direct and competition genetic effects in models with pens as fixed effects. From field data, relatively small estimates of variance attributable to competition effects were found by REML for Duroc-Hampshire and Landrace-Large White composite selected lines (Cassady and Van Vleck, 2004) and for Large White growing gilts (Arango et al., 2005). The objective of this study 
Table 1. Unadjusted means and SD for ADG (g)

\begin{tabular}{lrrr}
\hline \hline Item & Records & Mean & SD \\
\hline Line & & & \\
1 & 3,345 & 985.7 & 123.2 \\
2 & 2,805 & 988.5 & 122.1 \\
3 & 3,210 & 985.4 & 113.6 \\
4 & 1,875 & $1,016.8$ & 121.7 \\
Sex & & & \\
Male & 9,720 & $1,003.7$ & 118.9 \\
Female & 1,515 & 912.9 & 99.0 \\
Total & 11,235 & 991.5 & 120.5 \\
\hline
\end{tabular}

was to compare estimates of genetic variance for $\mathrm{ADG}$ with various models including competition effects.

\section{MATERIALS AND METHODS}

\section{Data}

Animal Care and Use Committee approval was not obtained for this study, because the data were obtained from an existing database.

Records of 11,235 pigs from 4 selected lines of swine from the Pig Improvement Company (Franklin, KY) were used to estimate variance components for $\mathrm{ADG}$ (g) on test. Data were from 4 test farms in North America collected during a 4-yr period (2000 through 2003). Records were available for pigs from 2 dam lines $(\mathrm{n}=$ 3,345 and 2,805 for lines 1 and 2) and 2 sire lines ( $\mathrm{n}=$ 3,210 and 1,875 for lines 3 and 4) from 2 birth farms and 2 nearby test farms. Pigs from the same line and sex were randomly grouped to pens of size 15 with average on-test ages of $71 \pm 6 \mathrm{~d}$ and $\mathrm{BW}$ of $30 \pm 5 \mathrm{~kg}$. Pigs were provided ad libitum access to feed and were measured for ADG until average off-test ages of 130 to 199 $\mathrm{d}$ and average off-test BW of 61 to $158 \mathrm{~kg}$.

The full pedigree file contained 43,585 animals; 9,720 males and 1,515 females had records. Seasons were classified as December through February, March through May, June through August, and September through November. Contemporary groups (cn), defined as test farm-year-season, were included in the models to account for common environmental conditions. The combination of test farm-pen-test date was used to define pen groups (pn). The areas of each pen were 12 and $14 \mathrm{~m}^{2}$ for 2 groups of birth-nearby test farm, respectively. Feed intake in some pens was measured with the Feed Intake Recording Equipment System (FIRE, Osborn Industries, KS). Other pens contained conventional multiplace dry feeders (one 3-place feeder per pen) or single-place wet-dry feeders for pen areas of 12 and $14 \mathrm{~m}^{2}$, respectively.

There were 45 contemporary groups and 749 pen groups with 4,896 litters from 770 sires. A sire was mated with 5 dams on average. The number of litters per dam averaged 1.3. Littermates within sex were distributed across pens. Most pens (88\%) had 3 to 5 pairs of full sibs of the same sex. Unadjusted mean ADG for tested animals was $991.5 \mathrm{~g}(\mathrm{SD}=120.5 \mathrm{~g})$ as reported in Table 1.

\section{Statistical Models and Analyses}

The equation for the linear model with initial test age as a covariate was

$$
\begin{gathered}
\mathrm{y}_{\mathrm{ijklmps}}=\text { line }_{\mathrm{k}}+\text { sex }_{\mathrm{l}}+\mathrm{cn}_{\mathrm{p}}+\mathrm{d}_{\mathrm{i}}+\sum \mathrm{c}_{\mathrm{j}}+\sum \mathrm{ce}_{\mathrm{j}} \\
+\mathrm{pn}_{\mathrm{m}}+\mathrm{lt}_{\mathrm{s}}+\mathrm{e}_{\mathrm{ijk} \mathrm{kmps}},
\end{gathered}
$$

where $\mathrm{y}_{\mathrm{ijklmps}}$ is $\mathrm{ADG}$ for animal $\mathrm{i}$ in pen group $\mathrm{m}$ belonging to line $\mathrm{k}$, sex class $\mathrm{l}$, and litter s within contemporary group $\mathrm{p} ; \mathrm{d}_{\mathrm{i}}$ is the direct additive genetic value of animal $\mathrm{i} ; \sum \mathrm{c}_{\mathrm{j}}$ and $\sum \mathrm{ce}_{\mathrm{j}}$ are the sums of competition (genetic and environmental) effects for 14 pen mates of animal $\mathrm{i} ; \mathrm{pn}_{\mathrm{m}}$ and $\mathrm{lt}_{\mathrm{s}}$ are assumed to be independent random pen and litter effects; and $\mathrm{e}_{\mathrm{ijklmps}}$ is an independent random residual effect. The litter effect was added to the model based on the suggestion of a reviewer and was included in all models, but did not change the conclusions based on models without litter effects. Those random effects are assumed to be from a $N(0, V)$ distribution, where

$$
V=\operatorname{Var}\left[\begin{array}{c}
d \\
c \\
c e \\
p n \\
l t \\
e
\end{array}\right]=\left[\begin{array}{cccccc}
A \sigma_{d}^{2} & A \sigma_{d c} & 0 & 0 & 0 & 0 \\
A \sigma_{d c} & A \sigma_{c}^{2} & 0 & 0 & 0 & 0 \\
0 & 0 & I_{n} \sigma_{c e}^{2} & 0 & 0 & 0 \\
0 & 0 & 0 & I_{m} \sigma_{p n}^{2} & 0 & 0 \\
0 & 0 & 0 & 0 & I_{s} \sigma_{l t}^{2} & 0 \\
0 & 0 & 0 & 0 & 0 & I_{n} \sigma_{e}^{2}
\end{array}\right],
$$

where $\sigma_{d}^{2}$ is the direct genetic variance; $\sigma_{d c}$ is the genetic covariance between direct and competition effects; $\sigma_{c}^{2}$ is the genetic competition variance; $\sigma_{c e}^{2}$ is the permanent environmental competition variance; $\sigma_{p n}^{2}$ is the random pen variance; $\sigma_{l t}^{2}$ is the random litter variance; $\sigma_{e}^{2}$ is the residual variance; $A$ is the augmented numerator relationship matrix among all animals in the pedigree; and $I$ are the identity matrices of appropriate order ( $n, m, s$, and $n$ for $c e, p n, l t$, and $e$ ) with $n$ the number of observations, $m$ the number of pens, and $s$ the number of litters. For the full model, the phenotypic variance with relationships among competitors ignored was computed as

$$
\sigma_{p}^{2}=\sigma_{d}^{2}+14 \sigma_{c}^{2}+14 \sigma_{c e}^{2}+\sigma_{p n}^{2}+\sigma_{l t}^{2}+\sigma_{e}^{2} .
$$

Relationships among animals could change from pen to pen and may have little effect on estimates of phenotypic variance (Van Vleck and Cassady, 2005).

For this model, environmental effects associated with records in a pen of $m$ would be the pen effect, the 
sum of environmental competition effects for 14 pen mates $\left(\sum c e_{j}\right)$, and direct residual effect of animal $i$ : $p n_{m}+\sum c e_{j}+e_{i}$. The covariance between environmental competition and residual effects $\left(\sigma_{c e, e}\right)$ was assumed to be zero. Hence, the matrix of environmental (co)variances among records of pigs in a pen would equal $\operatorname{Var}\left(p n_{m}+\sum c e_{j}+e_{i}\right)=\sigma_{p n}^{2}+14 \sigma_{c e}^{2}+\sigma_{e}^{2}$ on the diagonal and

$$
\operatorname{Cov}\left(p n_{m}+\sum c e_{j}+e_{i}, p n_{m}+\sum c e_{j^{\prime}}+e_{i^{\prime}}\right)=\sigma_{p n}^{2}+13 \sigma_{c e}^{2}
$$

on off-diagonal elements for records of pairs of animals in a pen. The proportion $(\rho)$, which corresponds to the correlation of environmental effects between records of pairs of competitors in a pen, is

$$
\rho=\frac{\sigma_{p n}^{2}+13 \sigma_{c e}^{2}}{\sigma_{p n}^{2}+14 \sigma_{c e}^{2}+\sigma_{e}^{2}} .
$$

Three reduced models, which also included genetic competition effects, are also discussed with respect to components of the correlation $(\rho)$ :

1) without environmental competition effects:

$$
\rho=\frac{\sigma_{p n}^{2}}{\sigma_{p n}^{2}+\sigma_{e}^{2}} ;
$$

2) without random pen effects:

$$
\rho=\frac{13 \sigma_{c e}^{2}}{14 \sigma_{c e}^{2}+\sigma_{e}^{2}} ; \text { and }
$$

3) without both environmental competition and random pen effects:

$$
\rho=0 .
$$

so that the environmental (co)variance matrix among records of pigs in a pen would be the identity matrix multiplied by $\sigma_{e}^{2}$. Bijma and Muir (2006) presented models with $\sigma_{c e, e}$ not equal to zero so that $\rho=\left(13 \sigma_{c e}^{2}+2 \sigma_{c e, e}\right) /\left(14 \sigma_{c e}^{2}+\sigma_{e}^{2}\right)$, which may not be positive.

Estimates of genetic parameters were obtained with the MTDFREML programs (Boldman et al., 1995) modified to include competition effects (Van Vleck and Cassady, 2004). Empirical SD for estimates of heritability for direct and competition effects were generated with the delta method by using the Taylor series expansion to approximate the variance of functions of variance components (e.g., Dodenhoff et al., 1998). Likelihood ratio tests were used to compare models by using the methods described by Stram and Lee (1994).

\section{RESULTS AND DISCUSSION}

Estimates of (co)variances and genetic parameters for ADG (g) with the 8 models are presented in Table 2. Relative to models without competition effects, convergence was relatively slow, with competition effects included because of much less sparseness in the mixed model equations. With the full model (model 1), the REML algorithm was not able to allow partitioning of total variance into environmental competition, pen, and residual components of variance, but it could separate variation attributable to litter effects and genetic variation attributable to direct and competition genetic effects. Consistent estimates of direct $(2,406)$, directcompetition (49), and genetic competition (18) (co)variance components $\left(\mathrm{g}^{2}\right)$ were obtained for all sets of starting values used. The estimate of genetic competition variance was small but significantly different from zero. The estimate of the genetic correlation between direct and competition genetic effects $\left(\mathrm{r}_{\mathrm{dc}}\right)$ was small (0.24). Thus, ignoring competition effects might not greatly bias predictions of direct genetic effects. In contrast to estimates of genetic variances, estimates of environmental competition, pen, and residual variances varied depending on initial starting values, but with no difference in the likelihoods (L, $-2 \log \mathrm{L}$ was used for comparison) for all starting values. Estimable combinations of variances were $\sigma_{p n}^{2}+14 \sigma_{c e}^{2}+\sigma_{e}^{2}$ and $\sigma_{p n}^{2}+13 \sigma_{c e}^{2}$, corresponding to the diagonal and off-diagonal elements of the environmental (co)variance matrix among records of pigs in a pen. The correlation $(\rho)$ between records of pigs in a pen, calculated from the proportion $\left(\sigma_{p n}^{2}+13 \sigma_{c e}^{2}\right) /\left(\sigma_{p n}^{2}+14 \sigma_{c e}^{2}+\sigma_{e}^{2}\right)$ by using estimates of the (co)variances, was 0.19 even with different starting values and estimates of variance components at convergence. Estimates of $\sigma_{p n}^{2}+13 \sigma_{c e}^{2}$ appeared to account for variation attributable to pen effects, and estimates of $\sigma_{c e}^{2}+\sigma_{e}^{2}$ seem to account for variation associated with residual effects.

The analysis excluding environmental competition effects (model 2) allowed partitioning of variances and covariances $(2,404,49,18,1,642,971$, and 7,045 for estimates of $\sigma_{d}^{2}, \sigma_{d c}, \sigma_{c}^{2}, \sigma_{p n}^{2}, \sigma_{l t}^{2}$, and $\sigma_{e}^{2}$ ) with similar estimates of genetic (co)variances and the same likelihood as with the full model. The numerator relationship matrix is important in partitioning the genetic variance components. With pen effects as random, relationships among animals within pens allow separation of direct genetic and pen variances. Similarly, relationships among animals across pens create genetic ties, allowing competition variances to be partitioned. The estimate of pen variance $(1,642)$ was relatively 
Table 2. Estimates of (co)variance components and genetic parameters for ADG (g) using all data

\begin{tabular}{lcccccccccc}
\hline \hline Model & $-2 \log \mathrm{L}$ & $\sigma_{d}^{2}$ & $\sigma_{d c}$ & $\sigma_{c}^{2}$ & $\sigma_{c e}^{2}$ & $\sigma_{p n}^{2}$ & $\sigma_{t t}^{2}$ & $\sigma_{e}^{2}$ & $h_{d}^{2}(\mathrm{SE})^{1}$ & $h_{c}^{2}(\mathrm{SE})^{2}$ \\
\hline $1^{3}$ & $115,124.872$ & 2,406 & 49 & 18 & $\mathrm{NA}$ & $\mathrm{NA}$ & 971 & $\mathrm{NA}$ & $0.20(\mathrm{NA})$ & $0.001(\mathrm{NA})$ \\
2 & $115,124.872$ & 2,404 & 49 & 18 & - & 1,642 & 971 & 7,045 & $0.20(0.08)$ & $0.001(0.005)$ \\
$2^{4}$ & $115,126.509$ & 2,434 & 0 & 20 & - & 1,724 & 940 & 6,976 & $0.20(0.08)$ & $0.002(0.005)$ \\
$3^{5}$ & $108,662.555$ & NA & NA & NA & - & Fixed & 967 & 7,032 & NA & NA \\
4 & $115,124.872$ & 2,410 & 48 & 18 & 126 & - & 971 & 6,916 & $0.20(0.08)$ & $0.001(0.005)$ \\
5 & $115,171.480$ & 2,412 & 150 & 83 & - & - & 1,013 & 7,139 & $0.21(0.03)$ & $0.007(0.006)$ \\
6 & $115,134.973$ & 2,502 & - & - & - & 2,276 & 941 & 6,946 & $0.20(0.02)$ & - \\
7 & $115,134.973$ & 2,507 & - & - & 175 & - & 942 & 6,769 & $0.20(0.05)$ & - \\
8 & $115,913.628$ & 3,817 & - & - & - & - & 1,866 & 6,949 & $0.30(0.03)$ & - \\
\hline
\end{tabular}

${ }^{1}$ Direct heritability: $h_{d}^{2}=\sigma_{d}^{2} / \sigma_{p}^{2}$, with $\sigma_{p}^{2}=\sigma_{d}^{2}+14 \sigma_{c}^{2}+14 \sigma_{c e}^{2}+\sigma_{p n}^{2}+\sigma_{l t}^{2}+\sigma_{e}^{2}(\operatorname{model} 1)$ or $\sigma_{p}^{2}=\sigma_{d}^{2}+14 \sigma_{c}^{2}+\sigma_{p n}^{2}+\sigma_{l t}^{2}+\sigma_{e}^{2}(\operatorname{model} 2)$ or $\sigma_{p}^{2}=\sigma_{d}^{2}+14 \sigma_{c}^{2}+14 \sigma_{c e}^{2}+\sigma_{l t}^{2}+\sigma_{e}^{2}(\operatorname{model} 4)$ or $\sigma_{p}^{2}=\sigma_{d}^{2}+14 \sigma_{c}^{2}+\sigma_{l t}^{2}+\sigma_{e}^{2}(\operatorname{model} 5)$ or $\sigma_{p}^{2}=\sigma_{d}^{2}+\sigma_{p n}^{2}+\sigma_{l t}^{2}+\sigma_{e}^{2}(\operatorname{model} 6)$ or $\sigma_{p}^{2}=\sigma_{d}^{2}+14 \sigma_{c e}^{2}+\sigma_{l t}^{2}+\sigma_{e}^{2}$ (model 7) or $\sigma_{p}^{2}=\sigma_{d}^{2}+\sigma_{l t}^{2}+\sigma_{e}^{2}$ (model 8), with SE computed by using the delta method. Standard error for $h_{d}^{2}$ with model 1 was not estimated because estimates of $\sigma_{c e}^{2}, \sigma_{p n}^{2}$, and $\sigma_{e}^{2}$ varied depending on starting values.

${ }^{2}$ Competition heritability: $h_{c}^{2}=\sigma_{c}^{2} / \sigma_{p}^{2}$, with SE computed by using the delta method. Standard error for $h_{c}^{2}$ with model 1 was not estimated because asymptotic estimates of (co)variances $\left(\sigma_{c e}^{2}, \sigma_{p n}^{2}\right.$, and $\left.\sigma_{e}^{2}\right)$ varied depending on starting values.

${ }^{3}$ Estimates were different (NA) depending on starting values, which showed that components of environmental variance could not be estimated.

${ }^{4}$ For model 2 with $\sigma_{d c}$ fixed as zero, $-2 \operatorname{logL}$ (where $\mathrm{L}$ is likelihood) increased slightly but not significantly $(P>0.05)$.

${ }^{5}$ Estimates (NA) were different depending on starting values, which shows that components of genetic variance could not be partitioned with pens as a fixed factor.

large compared with the estimate of $\sigma_{c}^{2}(18)$. With model 2 and $\sigma_{d c}$ fixed as zero, estimates of $\sigma_{d}^{2}$ and $\sigma_{c}^{2}$ and $-2 \log \mathrm{L}$ increased slightly, but were not significant $(P>$ 0.05). Van Vleck and Cassady (2005) concluded that estimates of $\sigma_{d}^{2}$ and $\sigma_{c}^{2}$ tended to increase with $\sigma_{d c}$ fixed as zero if the true covariance was negative and to decrease if the true covariance was positive. For this model, the estimate of variation attributable to pen effects would simply be the estimate of $\sigma_{p n}^{2}(1,642)$ and the estimate of variation attributable to residual environmental effects would be the estimate of $\sigma_{e}^{2}(7,045)$. The estimate of the correlation $\left[\rho=\sigma_{p n}^{2} /\left(\sigma_{p n}^{2}+\sigma_{e}^{2}\right)\right]$ between records of pigs in a pen, calculated from estimates of the variance components, was 0.19 .

The model with pens as fixed effects and without environmental competition effects (model 3) could not partition genetic variances. Estimates of competition genetic (co)variances were different depending on starting values, but all converged to the same logL. Because competition effects are confounded with pen effects, relationships among animals within pens may not be able to untangle the confounding of effects with pens considered to be fixed effects; however, a pattern was found based on equivalent models. With model 2 , the total of genetic effects for a record of individual $i$ is composed of the direct genetic effect and sum of competition effects associated with 14 competitors as follows:

$$
g_{i}=d_{i}+\sum_{j=1}^{14} c_{j}
$$

with $d \sim N\left(0, A \sigma_{d}^{2}\right)$. An equivalent expression for the total direct genetic effect for a record of animal $i$ is

$$
g_{i}=d_{i}-c_{i}+\sum_{j=1}^{15} c_{j}
$$

with $(d-c) \sim N\left[0, A\left(\sigma_{d}^{2}-2 \sigma_{d c}+\sigma_{c}^{2}\right)\right]$. When relationships among competitors were ignored, estimates of $\sigma_{d}^{2}-2 \sigma_{d c}+\sigma_{c}^{2}$ from using different starting values with model 3 were similar to the estimate of $\sigma_{d}^{2}$ with model 2 $(2,404)$. The estimates of $\sigma_{d}^{2}-2 \sigma_{d c}+\sigma_{c}^{2}$ with 3 sets of starting values for $\sigma_{d}^{2}, \sigma_{d c}$, and $\sigma_{c}^{2}$ were as follows:

1. $2,473-2(68)+8=2,345$,

2. $1,536-2(-351)+102=2,340$, and

3. $930-2(-537)+334=2,338$.

When pen effects were ignored (model 4), the smaller estimate of residual variance plus the estimate of $\sigma_{c e}^{2}$ was similar to the estimate of residual variance with model $2(6,916+126=7,042$ vs. 7,045$)$. The estimate of $13 \sigma_{c e}^{2}(13 \times 126=1,638)$ corresponded to the estimate of $\sigma_{p n}^{2}(1,642)$ from model 2 with similar estimates of genetic variances and the same likelihood for the full model and model 2. The estimate of the correlation $(\rho)$ between records of pigs in a pen, calculated from estimates of the variance components in the proportion (13 $\left.\sigma_{c e}^{2}\right) /\left(13 \sigma_{c e}^{2}+\sigma_{e}^{2}\right)$, was 0.19 , which was the same for the full model and for model 2 .

The analysis excluding both pen and environmental competition effects (model 5) resulted in inflated estimates of $\sigma_{d c}$ (49 vs. 150$)$ and $\sigma_{c}^{2}(18$ vs. 83$)$, with estimates of $\sigma_{d}^{2}$ and $\sigma_{e}^{2}$ only slightly affected compared with model 2. The SE for estimates of genetic competition 
variances also increased slightly (77.9 vs. 59.6). A simulation study by Van Vleck and Cassady (2005) showed that if the true pen variances were relatively large, ignoring pen effects might cause estimates of $\sigma_{d c}$ to be positive or greater than zero when the true $\sigma_{d c}$ was negative or near zero.

Ignoring competition (genetic and environmental) effects but including pen as a random effect (model 6) led to an increase in the estimate of pen variance by $39 \%$, with little change in estimates of direct genetic or residual variances. Van Vleck and Cassady (2005) also found overestimation of $\sigma_{p n}^{2}$ when the true direct-competition covariance was positive. They illustrated why $\sigma_{p n}^{2}$ would be overestimated based on the intraclass correlation with the assumption that the variance component for pen effects is equivalent to the covariance between records of any pair of animals in the same pen.

Overestimation of $\sigma_{p n}^{2}$ in the current study can be demonstrated based on their illustration. With 15 unrelated animals in a pen, the record of animal $i\left(y_{i}\right)$ adjusted for fixed effects and random litter effect could be presented as

$$
y_{i}=d_{i}+\sum_{j \neq i}^{15} c_{j}+p n_{m}+e_{i}
$$

with model 2 . The pen variance calculated as the covariance between records of animal $i$ and any competitor $i^{\prime}$ in the same pen would be $\operatorname{Cov}\left(y_{i}, y_{i^{\prime}}\right)=\sigma_{p n}^{2}+13 \sigma_{c}^{2}+2 \sigma_{d c}$. Therefore, the magnitude of overestimation of $\sigma_{p n}^{2}$ with model 6 with unrelated animals in a pen would be expected to be $13 \sigma_{c}^{2}+2 \sigma_{d c}$ from estimates of (co)variance components with model 2 as approximated by the intraclass correlation model. The estimate of the correlation $(\rho)$ between records of pigs in a pen, calculated from estimates of variance components for the proportion $\left(\sigma_{p n}^{2}\right) /\left(\sigma_{p n}^{2}+\sigma_{e}^{2}\right)$, was 0.25 , which was 0.06 larger than for the full model and for model 2.

The estimate of direct heritability with model 2 was 0.20 compared with the 0.15 reported by Arango et al. (2005). Based on the likelihood ratio test, model 6, which included random pen effects, was significantly better than model 5 , which included genetic competition effects, but not permanent competition environmental effects or pen effects. Model 5 seemed to slightly overestimate heritability for direct genetic effects (0.21).

With both pen and genetic competition effects ignored (model 7), the estimate of $\sigma_{c e}^{2}$ (175) increased significantly $(P<0.05)$, with little change in the estimate of $\sigma_{d}^{2}(2,507)$ compared with model 4 . The value of $-2 \log \mathrm{L}$ for model 7 was the same as for model $6(P>$ $0.05)$, and the estimate of $13 \sigma_{c e}^{2}(13 \times 175=2,275)$ corresponded to the estimate of $\sigma_{p n}^{2}(2,276)$ with model 6 .
The estimate of the correlation $(\rho)$ between records of pigs in a pen, calculated from estimates of variance components of the proportion $\left(13 \sigma_{c e}^{2}\right) /\left(13 \sigma_{c e}^{2}+\sigma_{e}^{2}\right)$, was 0.25 , the same as for model 6 .

Models 1 (full model), 2 , and 4 had the same values of $-2 \log \mathrm{L}(115,124.872)$ and models 6 and 7 had similar values of $-2 \operatorname{logL}(115,134.973)$, which may result from a high level of confounding among pen, environmental competition, and residual effects. Bijma and Muir (2006) estimated the correlation $(\rho)$ between environmental effects for records of pen mates and concluded that only the combined effect as correlated residuals within pen could be estimated, because variance attributable to pen effects was contained within the correlation.

For the simple model including only direct genetic, litter, and residual effects, but not including pen effects (model 8), the estimate of $\sigma_{d}^{2}$ increased to 3,817 and the estimate of $\sigma_{e}^{2}(6,949)$ decreased slightly in this study, but the estimate of $\sigma_{e}^{2}$ increased as reported by Van Vleck and Cassady (2005) with simulated records. The sum of estimates of $\sigma_{d}^{2}$ and $\sigma_{l t}^{2}$ with model 8 increased approximately by the estimate of $13 \sigma_{c}^{2}+\sigma_{p n}^{2}+2 \sigma_{d c}$ compared with model 2 or by the estimate of $\sigma_{p n}^{2}(2,276)$ compared with model 6.

Analyses using all data and subsets by line and sex had similar patterns for estimates of variance components with the various models. Estimates of direct heritability with model 2 were $0.20,0.27,0.14$, and 0.13 for lines 1 through 4, respectively. The estimates of heritability for genetic competition effects were from 0.000 to 0.002 for the 4 lines. The estimates of direct heritability with model 2 were 0.20 and 0.40 for males and females, respectively. Heritability of competition effects was significantly different from zero for males with a small estimate of heritability $(0.002 ; P<0.05)$, but was not significant for females $(P>0.05)$ with the estimate of heritability even closer to zero.

In conclusion, estimates of variance attributable to competition genetic effects were small, but small competition effects summed over the number of competitors might be important. Problems encountered when estimating (co)variance components for models including competition effects may be due partly to confounding of effects in the model. Relationships among animals within and across pens may provide information to untangle the confounding of effects. Environmental effects associated with competitors in a pen seem to be nearly completely confounded with pen effects. Results from this study suggest that either pen as an uncorrelated random factor or environmental competition effects as a permanent environmental factor should be included in the model to avoid bias in estimation of variances attributable to direct and competition genetic effects. Pen space, feeding system, and pedigree structure within and across pens could also affect vari- 
ation attributable to competition effects. Factors affecting estimates of variance attributable to competition effects need to be investigated and evaluated further before considering genetic competition effects in a selection program.

\section{LITERATURE CITED}

Arango, J., I. Misztal, S. Tsuruta, M. Culbertson, and W. Herring. 2005. Estimation of variance components including competitive effects of Large White growing gilts. J. Anim. Sci. 83:12411246.

Bijma, P., and W. M. Muir. 2006. Genetic analysis and improvement of traits affected by behavioural or other interactions among individuals. Proc. 8th World Congr. Genet. Appl. Livest. Prod. CD-ROM Commun. No. 17-02. Belo Horizonte, MG, Brazil.

Boldman, K. G., L. A. Kriese, L. D. Van Vleck, C. P. Van Tassell, and S. D. Kachman. 1995. A manual for use of MTDFREML. A set of programs to obtain estimates of variances and covariances [Draft]. USDA-ARS, Clay Center, NE.

Cassady, J. P., and L. D. Van Vleck. 2004. Estimation of (co)variance components due to genetic competition effects in pigs. J. Anim. Sci. 82(Suppl.2):38 (Abstr.).
Dodenhoff, J., L. D. Van Vleck, S. D. Kachman, and R. M. Koch. 1998. Parameter estimates for direct, maternal, and grandmaternal genetic effects for birth weight and weaning weight in Hereford cattle. J. Anim. Sci. 76:2521-2527.

Muir, W. M. 2005. Incorporation of competitive effects in forest tree or animal breeding programs. Genetics 170:1247-1259.

Muir, W. M., and A. Schinckel. 2002. Incorporation of competitive effects in breeding programs to improve productivity and animal well being. Proc. 7th World Congr. Genet. Appl. Livest. Prod. CD-ROM Communication No. 14-07. Montpellier, France.

Stram, D. O., and J. W. Lee. 1994. Variance components testing in the longitudinal mixed effects model. Biometrics 50:1171-1177.

Van Vleck, L. D., and J. P. Cassady. 2004. Modification of MTDFREML to estimate variance due to genetic competition effects. J. Anim. Sci. 82(Suppl.2):38 (Abstr.).

Van Vleck, L. D., and J. P. Cassady. 2005. Unexpected estimates of variance components with a true model containing genetic competition effects. J. Anim. Sci. 83:68-74.

Van Vleck, L. D., L. V. Cundiff, and R. M. Koch. 2007. Effect of competition on gain in feedlot bulls from Hereford selection lines. J. Anim. Sci. 85:1625-1633. 